\title{
Flow Simulation over a Bulbous Heat Shield of a Typical Launch Vehicle
}

\author{
Manoj R, Ranjith Kumar A, Gopalsamy Murugesan, P. Jeyajothiraj
}

\begin{abstract}
Numerical Simulation of flow field over a sharp and blunt nose cone bulbous heat shield are carried out. Software used for the simulation is ANSYS 19.2 student version. The Simulations are carried out in the Mach no. range 0.8 to 1.2 (transonic regime). Simulation results are analyzed in detail. Besides, Shock Strength on the heat shield for all the simulation results are obtained. Based on the studies, bulbous heat shield which gives least shock strength is recommended for the payload fairing configuration.
\end{abstract}

Keywords : Sharp and blunt nose cone, Bulbous heat shield, Numerical Simulation of flow field, Payload fairing configuration.

\section{INTRODUCTION}

The payload fairing in any launch vehicle is needed to protect the satellite from aerodynamic loading, aerodynamic heating and other environmental conditions during the ascent phase of the flight and to provide an aerodynamic forward surface Bulbous Heat Shields are essential for accommodating larger payloads on launch vehicle configurations. The flow field visualization over a bulbous payload shroud at transonic Mach number range is very useful to decide the geometrical configuration for minimum aeroacoustical loading, minimum buffeting load and minimum aerodynamic drag requirement .The terminal shock wave of sufficient strength intersecting with the boundary layer can cause flow separation and the flow field may become unstable as observed in the high speed, it is desirable to determine the location of the terminal shock as a function of transonic Mach numbers. The strength of terminal shock and the mechanism of its interaction are related to the specific configuration of the heat shield of satellite launch vehicle.

The features of the transonic flow field can be delineated through the theoretical and experimental investigations. It is characterized by a terminal shock, supersonic pocket on the cylindrical region of the heat shield, shock wave-turbulent

boundary layer interaction, and a separated bubble that may be caused by the shock wave-turbulent boundary layer on the

Revised Version Manuscript Received on 10, September 2019.

Mr. Manoj R, UG Scholar, Department of Aerospace Engineering, Karunya Institute of Technology and Sciences, Coimbatore, Tamilnadu, India.(Email: manomicheals@gmail.com).

Mr. Ranjith Kumar A, UG Scholar, Department of Aerospace Engineering, Karunya Institute of Technology and Sciences, Coimbatore, Tamilnadu, India.(Email: ranaranjith20@ gmail.com).

Mr. Gopalsamy Murugesan, Research Scholar, Department of Coimbatore, Tamilnadu, India.(Email: gsam19ni@gmail.com).

Dr.P.Jeyajothiraj, Professor, Department of Aerospace Engineering, Karunya Institute of Technology and Sciences, Coimbatore, Tamilnadu, India.(Email: jothirajpeter@karunya.edu) Aerospace Engineering, Karunya Institute of Technology and Sciences,

cylindrical section of the heat shield. In the boat-tail region, a local separation results due to sharp discontinuity in the longitudinal direction of the payload shroud. The regions of flow separation impose additional complexity to aerodynamic and structural design aspects .The pressure fluctuations that originated at the location of the normal shock wave within the regions of separation can cause buffeting problem. The occurrence of buffeting of vehicle during transonic range depends primarily on the geometrical parameters of the payload shroud. The complex flow field at the transonic speeds is also observed during the wind-tunnel testing of the bulbous heat shield. The present study employs a computational fluid dynamics approach to analysis a complex fluid dynamics problem of the launch vehicle in the transonic Mach number range. The time-dependent, compressible, turbulent Reynolds-averaged Navier-Stokes equations are solved using a finite volume discretization in conjunction with a three-stage Runge-Kutta time-stepping scheme.

Charles et.al [1] investigate the Steady and fluctuating pressures measured along the top center lines of three space-vehicle models with hammerhead-shaped profiles within the Mach number range from 0.60 to 1.17 . The results of the investigation showed that flow separation due to the hammerhead configuration can expose large areas of the vehicle to significant pressure fluctuations. R.C. Mehta et.al [2] analyzed the unsteady, turbulent, compressible, axisymmetric flow. Reynolds-averaged Navier-Stokes equations are solved for the flow past a bulbous payload shroud for a freestream Mach number of 0.95. A time-dependent numerical simulation is carried out using a finite-volume discretization technique. Senthikumar et.al [3] studied the shock movements on the heat shield. The extents of separation zones behind the boat tail region are also estimated. S.Parameshwari et.al [4] investigated the transonic flow field over launch vehicles with strap on boosters. They found that the location of strapon booster are critical due to presence of aerodynamic phenomena, such as shock-boundary layer interaction, subsequent flow separation.

Pranav Mahamuni et.al [5] analyzed the shock waves formed in the transonic region of flow, which makes the fairing the most unstable in this phase. Studied the methodology for reducing the unsteady pressure levels and hence also the aeroacoustical loading in the transonic region 
i.e. Mach number 0.7 to 1.2 . From their study it is found that the separation area as well as the shock strength must be reduced. K. Manokaran et.al [6] simulated the flow over various payload fairing configuration in transonic Mach numbers. This types of Hammerhead/Bulbous Payload Fairing (PLF) creates unsteady aerodynamic effects especially in the transonic Mach number regime. R.C. Mehta et.al [7] computed the aerodynamic coefficients for various bulbous heat shield of a typical satellite launch vehicle at supersonic speeds. Numerical simulations are carried out by solving time-dependent, three-dimensional, compressible Euler equations in conjunction with a finite volume scheme at freestream Mach number 1.2 and 1.8. M Prasath et.al [8] fluctuating pressure measurements out over heat shield, boat tail and on core cylinder region of a generic launch vehicle having bulbous heat shield and strap-on configuration. Hence the understanding of flow field with separation and reattachment is of immense importance in design and control aspects of launch vehicles.

\section{METHODOLOGY \& RESULTS}

A.Launch Vehicle Nose Cone Configuration for PLF.

General launch vehicle nose cone geometrical configuration illustrated in figure 1 .

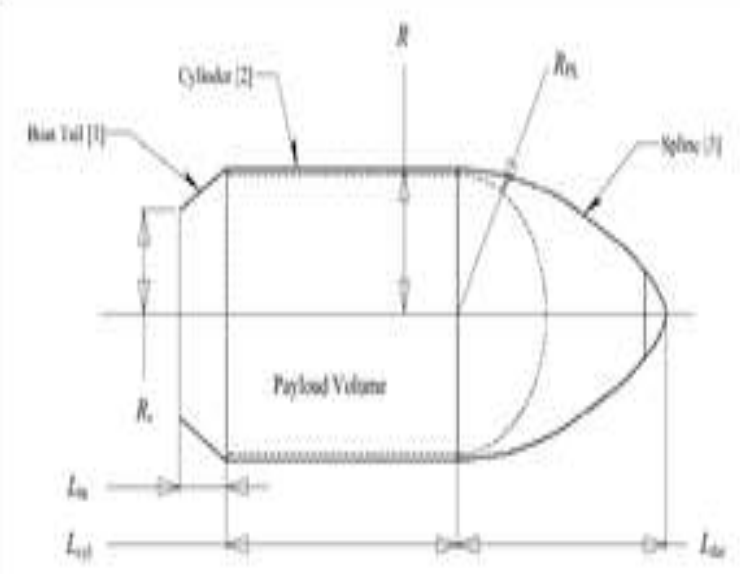

Fig.1 General Nose cone geometrical configuration.

\section{B. Types of PLF Configurations}

A very common nose-cone shape is a simple cone. This shape is often chosen for its ease of manufacture. More optimal, streamlined shapes (described below) are often much more difficult to create. The sides of a conic profile are straight lines.

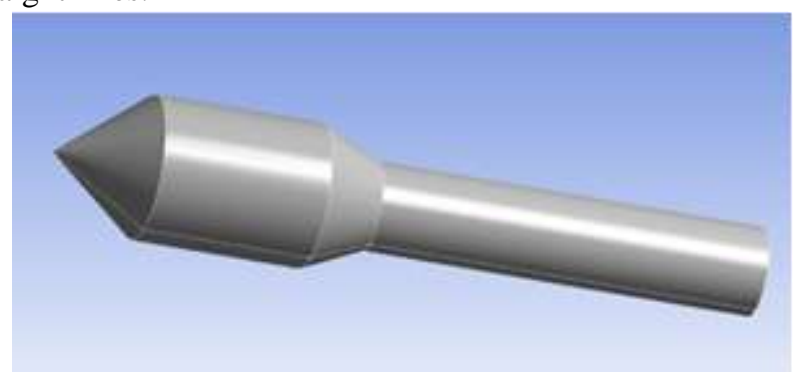

Fig.2 Sharp nose cone PLF

A conical nose is often blunted by capping it with a segment of a sphere. The tangency condition is implemented where the sphere meets the cone.

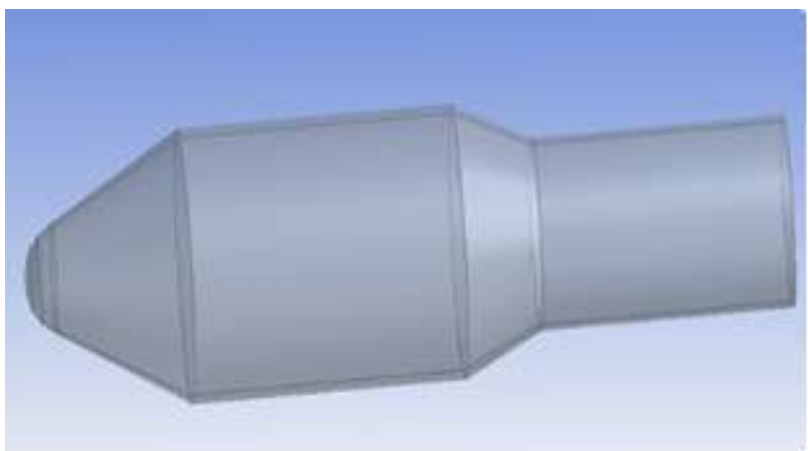

Fig.3: Blunt nose cone PLF

The idea of this research work is to understand the effects of shock at different locations in a different PLF configurations and to identify the variation trends of difference parameters like pressure distribution over the heat shield fairing, Shock location etc.,. The objective of this series of computational analysis is to obtain the flow fields that are generated due to the shock taking place in the heat shield for study the effects of shock wave movements on the nose cone body, obtain the flow parameters from the simulations and derive the shock strength.

\section{Geometry Considerations}

The Geometry taken are a simple sharp nose cone and blunt nose cone. The dimensions of the geometry configuration as follows:

- Sharp nose cone dimensions:

Total length $=150 \mathrm{~mm}$.

Nose cone angle $=29.64^{\circ}$.

Cylinder diameter $=24 \mathrm{~mm}$.

Cylinder length $=58.63 \mathrm{~mm}$.

Boat tail angle $=142.74^{\circ}$.

- Blunt nose cone dimensions:

Total length $=150 \mathrm{~mm}$.

Nose cone angle $=29.36^{\circ}$.

Cylinder diameter $=21.41 \mathrm{~mm}$.

Cylinder length $=53.76 \mathrm{~mm}$.

Boat tail angle $=127.94^{\circ}$.

D.Modelling of the geometries

Two different geometries are modelled, as sharp nose cone and blunt nose cone.

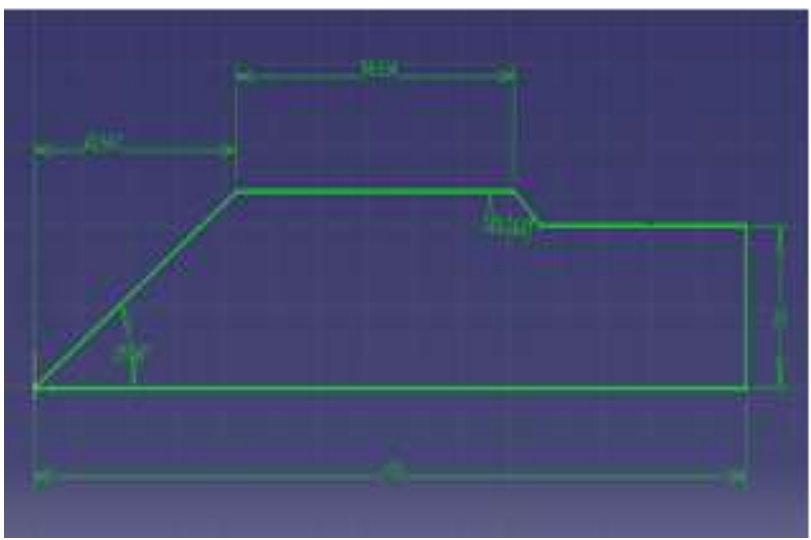

Fig.4 General Model of the sharp nose cone 


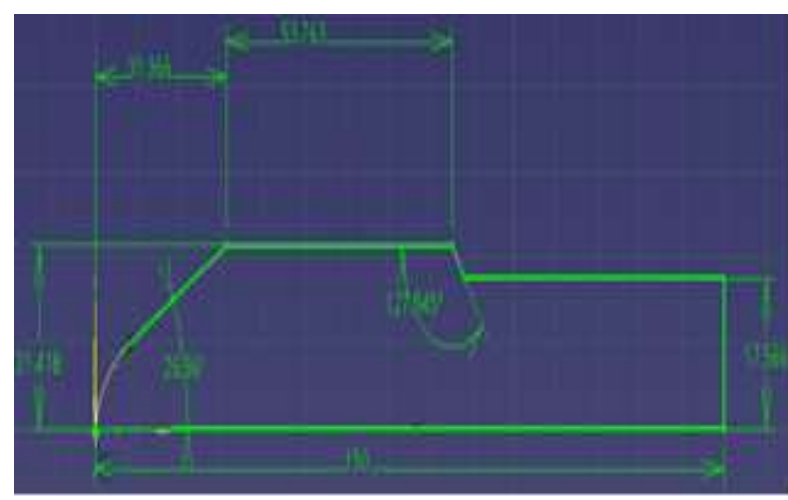

Fig.5 General Model of the blunt nose cone

\section{NUMERICAL SIMULATIONS}

The flow simulations require the following step

1. Modelling of the geometries.

2. Meshing the geometries and grid/mesh generation in the computational domain.

3. Solving the unsteady 3- Dimensional Navier-Stokes equations using finite volume method to obtain the steady state converged results.

Step 3 further requires

a. Turbulence modelling and

b. Boundary condition.

Spalart- Almarar turbulence model is used in these simulation. Velocity inlet, pressure outlet and wall boundary conditions are utilized to obtain steady state solution.

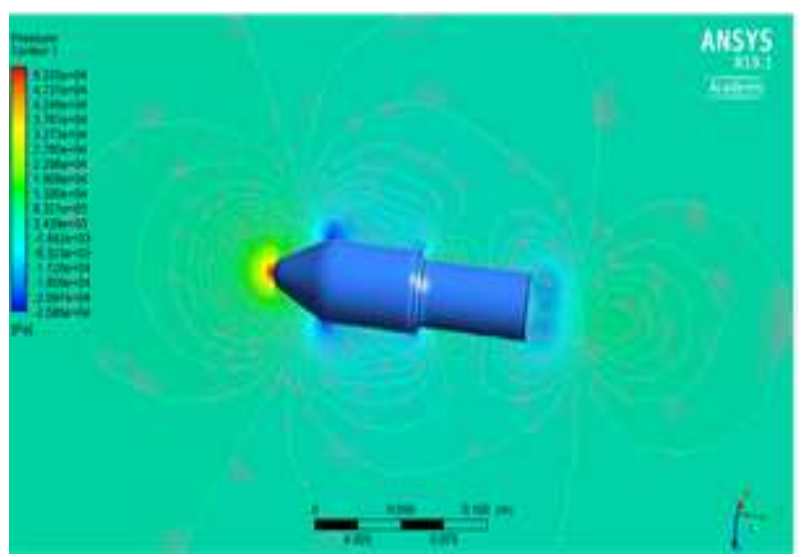

Fig.6 Pressure distribution over blunt nose cone at 0.9 Mach

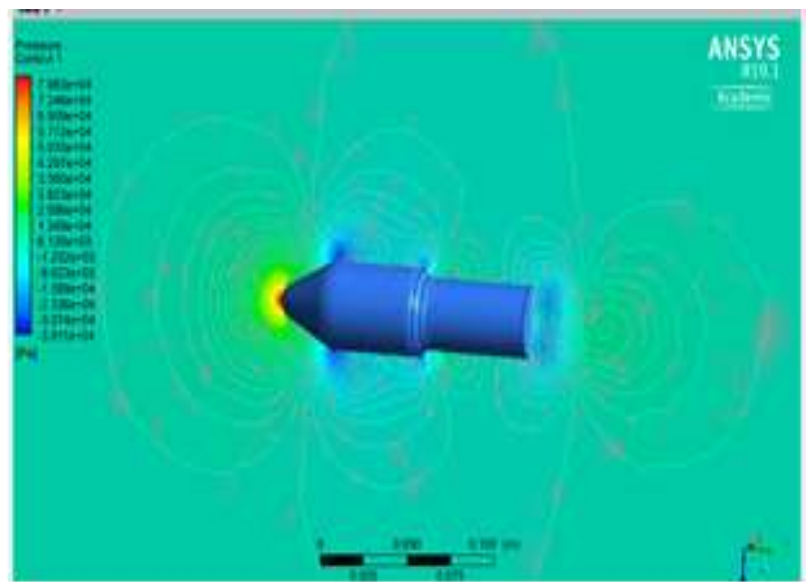

Fig.7 Pressure distribution over blunt nose cone for 1.0 Mach

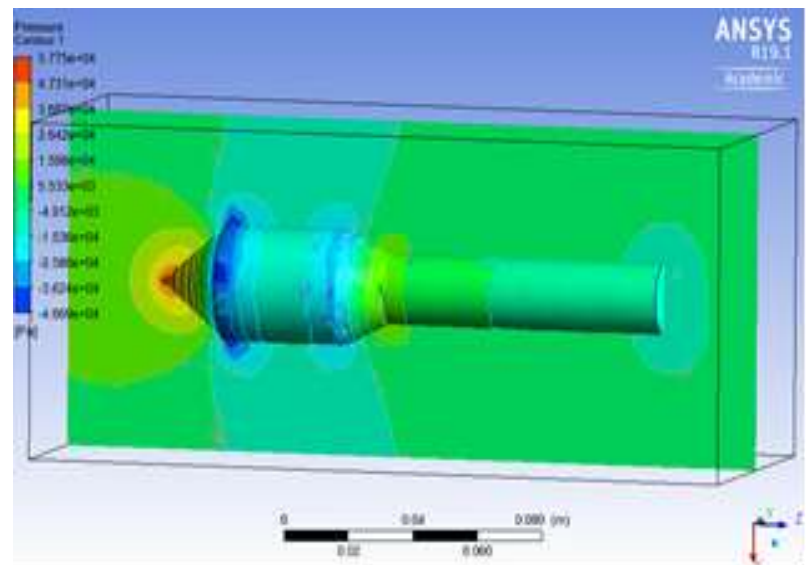

Fig.8 Pressure distribution over sharp nose cone for 1.0 Mach

Pressure distribution over blunt nose cone at $\mathrm{M}=0.9$ and $M=1.0$ are compared in Figure 6 and Figure 7. The stagnation pressure is higher for $\mathrm{M}=1$. For sharp nose cone, at $\mathrm{M}=1.0$ the stagnation pressure is lower than that of blunt nose for the same Mach number shown in Figure 7 and Figure 8.

\section{RESULTS AND DISCUSSIONS}

Pressure distribution over the blunt nose cone along the longitudinal axis for different Mach number are given in Figure 6 to 12 .

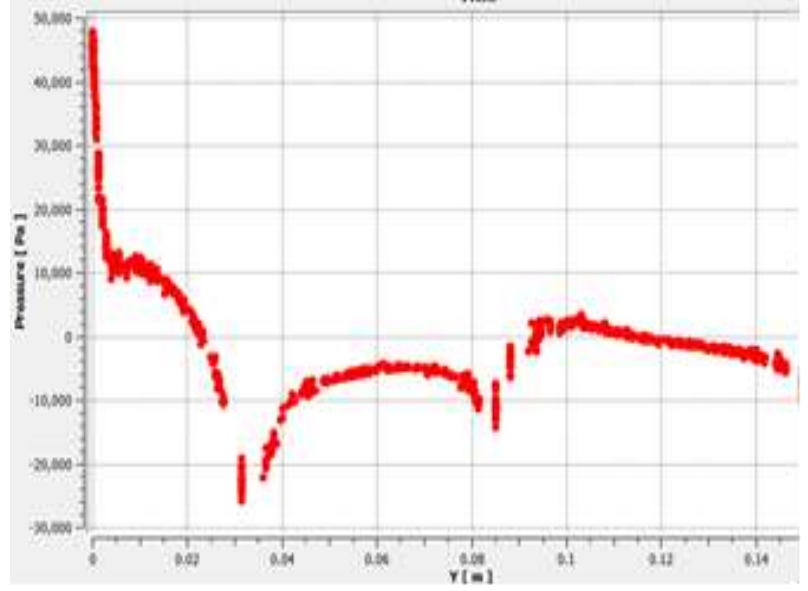

Fig.9 Pressure distribution for 0.9 Mach

Pressure distribution at 0.9 Mach shown in Figure 9. Nose cone center stagnation pressure $49 \mathrm{kPa}$, The pressure decrease continuously in the spherical nose cap and reaches a value of $10 \mathrm{kPa}$ at the curvature discontinuity location between spherical nose cap and nose cone. Pressure continues to decrease and reaches a minimum of about -25 $\mathrm{kPa}$ with a drastic drop at the nose cone cylinder junction due to expansion at this location. The pressure tries to recover to free stream value and reaches $-7 \mathrm{kPa}$ at the end of the cylindrical section. Since flow encounter another expansion corner at the cylinder-boat tail function and pressure drops to slightly and recover back to free stream in the cylindrical portion after the boat tail. 


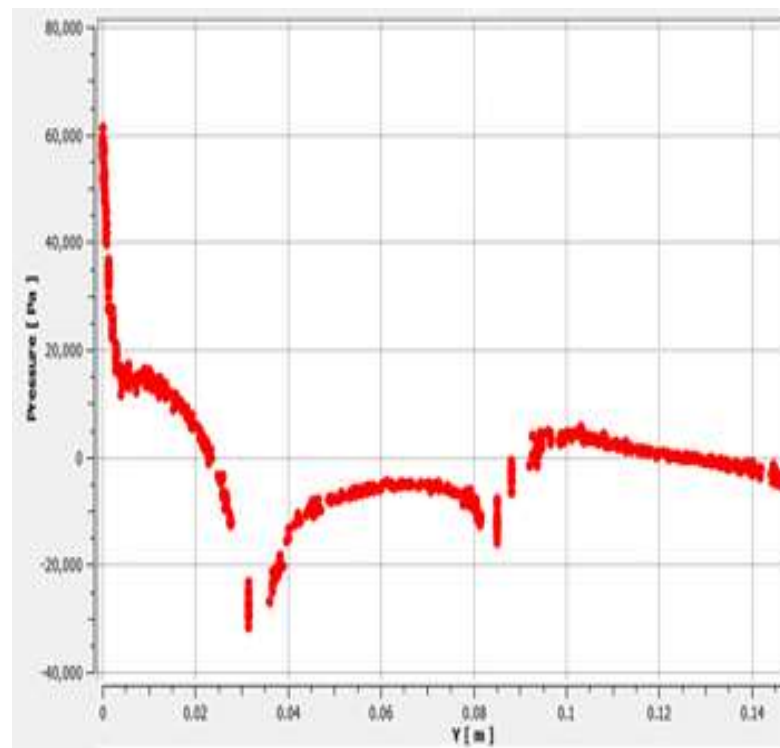

Fig.10 Pressure distribution for 1.0 Mach

Pressure distribution at 1.0 Mach shown in Figure 10. Nose cone center stagnation pressure $62 \mathrm{kPa}$, The pressure decrease continuously in the spherical nose cap and reaches a value of $15 \mathrm{kPa}$ at the curvature discontinuity location between spherical nose cap and nose cone. Pressure continues to decrease and reaches a minimum of about -30 $\mathrm{kPa}$ with a drastic drop at the nose cone cylinder junction due to expansion at this location. The pressure tries to recover to free stream value and reaches $-5 \mathrm{kPa}$ at the end of the cylindrical section. Since flow encounter another expansion corner at the cylinder-boat tail function and pressure drops to slightly and recover back to free stream in the cylindrical portion after the boat tail.

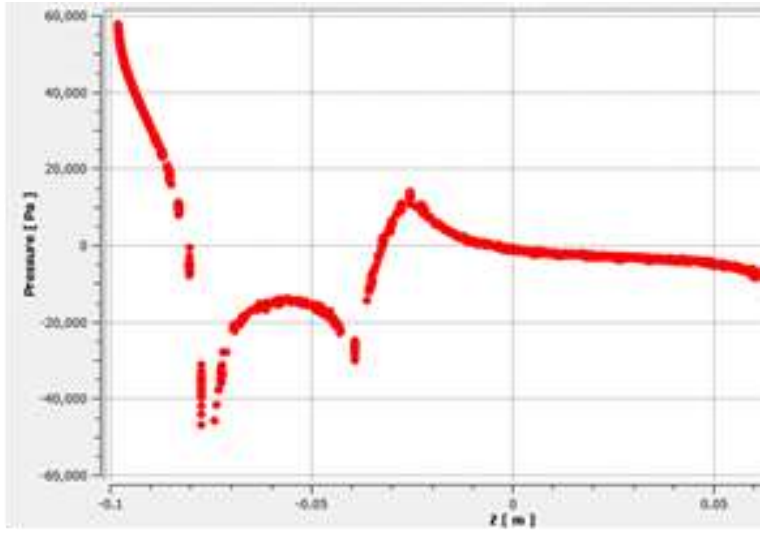

Fig.11 Pressure distribution for 0.9 Mach

Pressure distribution over the sharp nose cone at 0.9 Mach shown in Figure 11. Nose cone center stagnation pressure 58 $\mathrm{kPa}$, the pressure decrease continuously up to the junction of nose cone and cylinder and absent of effect of the spherical nose cap clearly shown in Figure 11. Pressure continues to decrease and reaches a minimum of about $-45 \mathrm{kPa}$ with a drastic drop at the nose cone cylinder junction due to expansion at this location. The pressure tries to recover to free stream value and reaches $-10 \mathrm{kPa}$ at the end of the cylindrical section. Since flow encounter another expansion corner at the cylinder-boat tail function and pressure drops to slightly and recover back to free stream in the cylindrical portion after the boat tail.

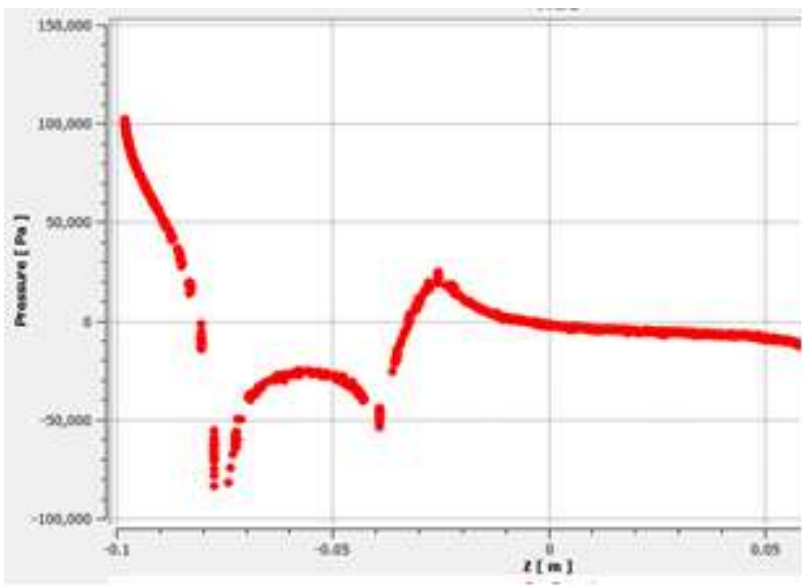

Fig.12 Pressure distribution for 1.0 Mach

Pressure distribution over the sharp nose cone at 1.0 Mach shown in Figure 12. In the Sharp nose cone normal shock stands close (Almost attached) to sharp leading edge of the nose. Nose cone center stagnation pressure $100 \mathrm{kPa}$, Pressure loss to the higher in blunt nose cone compare to the sharp nose cone. Pressure continues to decrease and reaches a minimum of about $-80 \mathrm{kPa}$ with a drastic drop at the nose cone cylinder junction due to expansion at this location. The pressure tries to recover to free stream value and reaches -25 $\mathrm{kPa}$ at the end of the cylindrical section. Since flow encounter another expansion corner at the cylinder-boat tail function and pressure drops to slightly and recover back to free stream in the cylindrical portion after the boat tail.

\section{CONCLUSION}

Detail study has been carried out for bulbous heat shield with blunt and sharp nose cones. Based on comparing the pressure distributions, the following conclusions are derived

1. Stagnation pressure of sharp nose cone and blunt nose cone are $100 \mathrm{kPa}$ and $62 \mathrm{kPa}$ at 1.0 Mach number. It clearly state the pressure loses in the blunt nose cone is higher than the sharp nose cone due to bow shock wave forms in front of the spherical cone.

2. Due to high stagnation pressure in blunt nose cone, the lesser pressure drop in the nose cone and cylinder junction compare to the sharp nose cone.

3. Blunt nose cone is preferable not only from the heat transfer point of view but also from the structural load aspects also.

\section{REFERENCES}

1. Charles F. Coe and James B. Nute, "Steady and Fluctuating Pressures at Transonic Speeds on Hammerhead Launch Vehicles", Technical Memorandum, X-778, Ames Research Center, Moffett Field, Calif, December-1962.

2. R.C.MEHTA, "Unsteady Pressure Fluctuations in the Boat tail Region of a Heat Shield", Noorul Islam University, Article?in?Aerospace Science and Technology Volume (4) Issue (2):91-102 ,Published on December 1999. 
3. Senthikumar, Mahesh M.S. and P.Jeyajothiraj, "Effects of diameter increase on the flow and aeroacoustic characteristics of bulbous heat shield at transonic mach numbers", The 2nd International Symposium on Recent advance in experimental fluid mechanics, Koneru Laxshmiah College of Engineering, Vaddeswaram, Andra Pradesh, arch 3-6,2008, PP: 196-201.

4. S.Parameshwari, J.Bruce Ralphin Rose, G.Vidya, K. Manokaran, Peter Jeyajothiraj, "Simulation of transonic flow over a multibody launch vehicle", International Conference on Advanced Research in Mechanical Engineering(ICARME), Vol.44, No.1, PP:123-134, Coimbatore, India, 21st April 2013.

5. Pranav Mahamuni and Pratik Bhansali.., "Aerodynamic Study of Payload Fairing", International Journal of Innovative Research in Science, Engineering and Technology. Vol. 4, Issue 3, PP: 49-51, March 2015.

6. K Manokaran, G Vidya, M Harish, P Jeyajothiraj, "Simulation of flow over various payload fairing configuration in transonic Mach numbers", Proceedings of the 23rd National Convention of Aerospace Engineers, Vol2, No.3, PP: 34-36, Nov.24-25, 2015, Hyderabad.

7. R.C.MEHTA, "Aerodynamic Design of Payload Fairing of Satellite Launch Vehicle", Noorul islam university,Article in International Review of Aerospace Engineering Volume(8)Issue(5):Pg:167, October 2015.

8. M Prasath, K Hariharan, V R Ganesan, M M Patil ,T Arun Kumar \& K N Murugan , "Effect of Strap-On Nose Shape on Aeroacoustics of a Bulbous Heat Shield Launch Vehicle", Proceedings of the 6th International and 43rd National Conference on Fluid Mechanics and Fluid Power , (FMFP)2016-PAPER NO.574. December 15-17, 2016, MNNITA, Allahabad, U.P., India.

9. Maryam Ozair, Shamoon Jamshed, M.Nauman Qureshi , "Time-Accurate CpFD Simulation of Transonic Flow over a Hammerhead Nose Cone Configuration" ,Institute of Space Technology (IST), Karachi, Pakistan, ICASE 2017.

\section{AUTHORS PROFILE}

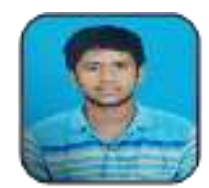

R Monoj, UG Scholar, B.Tech. Aerospace Engineering, Karunya Institute of Technology and Sciences, Coimbtore.

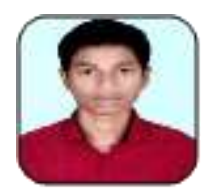

Ranjith Kumar A, UG Scholar, B.Tech Aerospace Engineering, Karunya Institute of Technology and Sciences, Coimbtore.

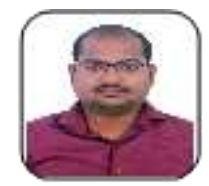

Gopalsamy Murugesan, Research Scholar, Department of Aerospace Engineering, Karunya Institute of Technology and Sciences, Coimbatore.

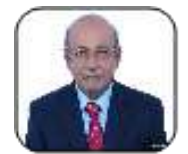

Dr. P. Jeyajothiraj, Professor, Department of Aerospace Engineering, Karunya Institute of Technology and Sciences, Coimbatore. Former Scientist ' $G$ ' from Indian Space Research Organization (ISRO). Specialization: Aerodynamics, Gas Dynamics, Experimental Aerodynamics, Acoustics and Aeroacoustics. 